\title{
Empowering a State's Development of a Knowledge Society
}

\author{
Arkalgud Ramaprasad, Ph.D. \\ Professor, University of Illinois at Chicago \\ 601 South Morgan Street, M/C 294 \\ Chicago, IL 60607-7124, USA \\ E-mail: prasad@uic.edu \\ Prof. M.K. Sridhar, Ph.D. \\ Member-Secretary \& Executive Director \\ Karnataka Knowledge Commission \\ Government of Karnataka \\ Bangalore 560 233, India \\ E-mail: bharathvasi@gmail.com
}

\begin{abstract}
This paper presents an ontological framework for empowering a state's development of a knowledge society. It is an adaptation of the framework for the role of Triple Helix (TH) in the global agenda for innovation, competitiveness, and sustainability. The adaptation is based on the experience of the Karnataka Knowledge Commission (KKC) in India - Karnataka is a state in India - and related literature. The discussion shows how the framework can be used to advance the vision of developing a knowledge society in Karnataka and elsewhere around the globe.
\end{abstract}

Sub themes: Triple Helix in developing countries; Regional/Local economic and social development; Triple Helix model

Keywords: Knowledge Commission, Knowledge Society, Knowledge for Development, Ontological Design

Copyright of the paper resides with the authors. Submission of a paper grants permission to the 8th Triple Helix International Scientific and Organizing Committees to include it in the conference material and to place it on relevant websites. The Scientific Committee may invite papers accepted for the conference to be considered for publication in Special Issues of selected journals. 


\section{Empowering a State's Development of a Knowledge Society}

Sub themes: Triple Helix in developing countries; Regional/Local economic and social development; Triple Helix model

Keywords: Knowledge Commission, Knowledge Society, Knowledge for Development, Ontological Design

\section{Introduction}

Every society is a knowledge society (McElhinney 2005; Casey 2006; Bhargava 2007). Like Yin and Yang, a society and its knowledge are inseparably intertwined. Their symbiotic relationship can be positively-reinforcing, non-reinforcing, or negatively-reinforcing and as a consequence a society and its knowledge may develop, stagnate, or deteriorate in synchrony (Anderson 2007). The history of civilization is replete with examples of countries and regions which developed to great heights driven by knowledge of science, mathematics, and technology and their positively reinforcing effects on society, and vice versa. Many of them stagnated, deteriorated and ultimately died when the symbiosis became non-reinforcing or negatively-reinforcing due to internal forces, external forces, or environmental changes.

Like many civilizations across the world, India, through the millennia, has gone through many cycles of development, stagnation, and decline. It has had periods of intellectual, social and economic glory sustained by sophisticated knowledge and an enlightened society for the time - knowledge from those periods is invaluable to this day. It has also had extended periods of stagnation and decline where the knowledge from the past has been lost to its own people, and the inflow of new knowledge from within and outside has been sparse and difficult. During these periods the society fossilized and unfortunate legacies of those periods persist to this day. The country is now in a phase of rapid development of its knowledge and society, drawing upon the best and eliminating the worst from the past (McElhinney 2005; Pillania 2005; Tripathi 2006; Bhargava 2007; Radhakrishnan 2007; Tripathi 2007; Rao and Malhan 2008; National Knowledge Commission 2009). The challenge for India is: How can a positivelyreinforcing symbiosis between its knowledge and society be restored and renewed?

Karnataka is a large state in South India with an area of about 200,000 square kilometers and a population of about 53 million. It has a long and rich cultural, social, and economic history, a diverse population, a variety of natural resources, a very strong industrial and technological base, and a good primary, secondary and tertiary education infrastructure. It has constituted the Karnataka Knowledge Commission (KKC) to mobilize efforts for its transformation into a knowledge society (Karnataka Knowledge Commission 2009; Karnataka State Gazette Notification September 5, 2008). Drawing upon the experience of planning and implementing KKC this paper addresses the question: How can one empower a state's development of a knowledge society? The answer to the question would be of interest to many regions and countries which are seeking a transformation similar to Karnataka’s.

An ontological framework for developing an empowerment strategy forms the core of this paper. It is an adaptation of the framework for the role of Triple Helix (TH) in the global agenda for innovation, competitiveness, and sustainability (Ramaprasad and La Paz 2009). The adaptation integrates the experience of KKC with the literature on the development of a knowledge society and TH. The framework can be used to advance the vision of development of knowledge societies around the globe.

\section{State of the Art}

Knowledge society, knowledge-based society, knowledge economy, and knowledge-based economy are terms frequently used to describe the emergence of knowledge as the dominant resource for development in place of capital and labor (McElhinney 2005; Nokkala 2005; Rochdi 2005; Britz, Lor et al. 2006; Casey 2006; Jakobi 2007; Kalfoglou 2007; O'Hara 2007; Mioduser, Nachmias et al. 2008). The unique properties of knowledge - for example, the relative ease with which it can be transmitted, translated, duplicated, and distributed especially with the modern information technology - has made it an attractive resource for transforming a society. It is these properties which have been central to the development of the extremely successful outsourcing to India (software), China (manufacturing), Taiwan (electronic chips), and other countries. 
There is an emerging body of literature on knowledge society and its development at a time when the definition of such a society is itself evolving. Almost all the papers highlight the importance of ICT (Internet and Computer Technology) in the development of the knowledge society; many of them highlight the role of primary, secondary, and tertiary education in such a society; a few of them discuss the importance of TH partnerships (Rochdi 2005; Britz, Lor et al. 2006; Tripathi 2006; Tripathi 2007; Mioduser, Nachmias et al. 2008; Pujar, Kamat et al. 2008; Rao and Malhan 2008; Saloma-Akpedonu 2008; Ghosh 2009). However, there is little consensus on the strategy for development of a knowledge society (World Development Report 1998/1999; McElhinney 2005; Anandakrishnan 2007; Kalfoglou 2007; Radhakrishnan 2007).

India was one of the first countries to constitute a National Knowledge Commission focusing on access, concepts creation, applications and services perspectives of a Knowledge Society (National Knowledge Commission 2006; National Knowledge Commission 2006; National Knowledge Commission 2009). Apart from the Knowledge Commission's own publications there has emerged a body of literature critiquing its recommendations and their implementation (Anandakrishnan 2007; Bhargava 2007; Tilak 2007). The final assessment of the Commissions impact will likely take quite a few more years; there is however a number of lessons which can be learnt from the results to date.

The Karnataka Knowledge Commission (KKC) was the first such body constituted in an Indian state (Karnataka Knowledge Commission 2009; Karnataka State Gazette Notification September 5, 2008). It was constituted in 2008 under the aegis of the Chief Minister's Office - the Chief Minister is the highest elected representative in the state. The rationale for its establishment was as follows:

- To move from the paradigm of education to the paradigm of knowledge;

- To provide wider perspective for education by bringing about more holistic and integrated approach and reforms in and outside education;

- To drive the agenda of Karnataka development through knowledge and beyond economics;

- To position Karnataka as an innovative and proactive leader of not just reform but development also; and

- To promote out-of-box thinking and perspective among all concerned.

The commission adopted the following cardinal principles in fulfilling the above mandate:

- Development of all forms of knowledge- modern as well as traditional;

- Modernization without westernization;

- Development through knowledge;

- Integrated and holistic linkages between and across sectors; and

- Wider platform and framework for reform and development.

In this context its terms of reference were to:

- Build excellence in the educational system to meet the knowledge challenges of the 21st century and increase Karnataka's competitive advantage in fields of knowledge;

- Promote creation of knowledge in all formal and non-formal educational, scientific and knowledge institutions of Karnataka;

- Improve the leadership and management of educational and knowledge institutions of Karnataka;

- Promote knowledge applications in agriculture, rural development, health, industry and other areas;

- Enhance the use of knowledge capabilities in making government an effective service provider to the citizen and promote widespread sharing of knowledge to maximize public benefit; and

- To promote inter-sectoral interaction and interface with the objective of preservation, access, new concepts, creation, application, dissemination, outreach and services relating to knowledge.

Today a few other countries and states in India have adopted the concept and each seeks to develop a target geographical area by leveraging knowledge (Maria de Lourdes, Minoo et al. 2004; Mohrman 2005; Commission of the European Communities 2006; Commission of the European Communities 2006; Weber 2006; Frank and Meyer 2007). While all of them recognize the importance of the TH relationships in leveraging knowledge there is no comprehensive framework for doing so and consequently their efforts are likely to be fragmented. This paper proposes an ontological framework to fill the lacuna and help develop an integrated strategy. 


\section{'Big Picture' of Strategy}

The problem of empowering a state's development of a knowledge society is complex and challenging. It can be formulated in many ways; the formulation will determine the strategy for its solution. If it is too narrowly formulated the strategy can be partial and ineffective; if it is too broadly formulated the strategy can be impractical and unwieldy. The formulation should include the 'big picture' with the 'details'. It "should encapsulate the complexity of the problem but yet be parsimonious and practical to be used for management. It should enable the deconstruction of the problem into manageable parts and reconstruction of an overall solution from the solutions to the parts. It should be a map which captures the ['big picture'] and allows the analyst to move between the whole and the parts, between the macro and the micro, and experience and abstraction as necessary.” (Ramaprasad and Papagari 2009, p. 2) Ideally the formulation "...has to be plastic. It should be capable of being molded differently by different stakeholders. It should be flexible and adaptable while retaining its integrity and coherence. It should accommodate multiple approaches to, or logics of, decomposition and recomposition - all of which may be equally valid. The validity of one need not affect the validity of another. Yet, any selected logic has to be coherent and complete. It should be possible to extend it, modify it, and let it evolve rapidly. It should also permit the expression of different perspectives while at the same time permitting the comparison and contrast, abstraction and magnification, and integration and synthesis of these perspectives." (Ramaprasad and Papagari 2009, p. 2)We propose an ontology which fulfills these requirements and assess its face-validity of the through examples from KKC projects.

Triple Helix Partnerships

\begin{tabular}{llll}
\cline { 2 - 3 } Managing & Entities 1 & Entities 2 & Relationships \\
Introducing & University & Uniwersity & Independence \\
Enhancing & Industry & Industry & Interaction \\
Regulating & Government & Government & Cooperation \\
Inhibiting & & Collaboration \\
Eliminating & & Symbiosis
\end{tabular}

Illustrative Triple Helix Components

Introducing university-government collaboration for knowledge generation for economic development Regulating industry-university interaction for knowledge application for health care development. Enhancing industry-government cooperation for knowledge application for social development.

\section{Methodology}

The mandate of the KKC has a strong correspondence to the role of the TH in the global agenda for innovation, competitiveness, and sustainability. As such, the general TH ontology shown in Figure 1 (Ramaprasad and La Paz 2009) can be adapted to the vision and mission of KC. This paper presents an adaptation - a product of the joint effort of one of the authors of the TH ontology and the Member-Secretary and Executive Director of KKC.

The Triple Helix Ontology is composed of three principal axes: (a) Managing, (b) TH partnerships, and (c) Outcomes. The outcomes are defined by two component axes: (a) Functions and (b) Fields. Thus the outcomes could be 'knowledge generation for education development', 'knowledge application for environmental development', or a subset of the 25 possible combinations. The taxonomies of Functions and Fields can be modified to generate more or less combinations which fit a context.

The Triple Helix Partnerships are defined by three axes: the two entities in the partnership and the relationships between them. Thus a TH partnership may consist of a University-Industry Collaboration [for research] with Industry-Government Cooperation [on funding]. The Outcomes of these partnerships are defined by the corresponding Functions and Fields. Thus the University-Industry Collaboration may 'Generate knowledge for Health Care development' and the Industry-Government Cooperation may aid 'knowledge Exchange for Education development'. 
The methodology for adapting the TH ontology is grounded in (a) an extensive, systematic review of published literature on KC including journal articles, newspaper articles, web sites, and reports (b) public memos, reports, presentations and other documents of the KKC, and (c) personal knowledge of the Member-Secretary and Executive Director of the KKC. The objective of adaptation is to modify the TH ontology to the minimum extent possible and maintain its parsimony while adapting it to the vision and mission of KKC. The validity of the adaptation is judged by whether the proposed ontology: (a) encapsulates the logic of KKC, (b) facilitates realization of the vision of KKC (c) provides better focus for the entire work of KKC, and (d) provides a framework for consultation with KKC stakeholders.

The adapted ontology for empowering a state's development of a knowledge society is shown in Figure 2 below. The changes are as follows:

1. The first dimension has been renamed 'Leading' instead of 'Managing' - consonant with the proactive role of commissions like KKC.

2. The category of 'Facilitating' has been added to the Leading dimension considering its advisory role.

3. The Entity 1 and Entity 2 dimensions have been renamed as Sector 1 and Sector 2 consonant with the scope and

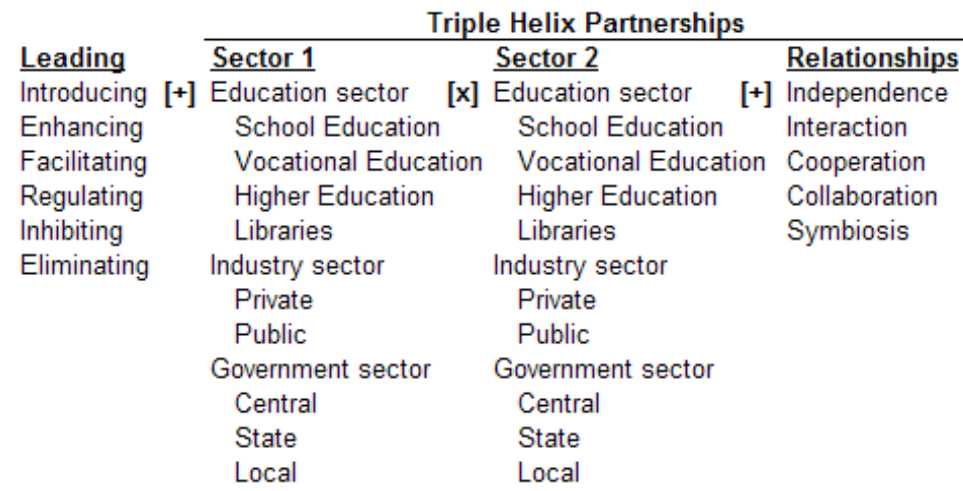

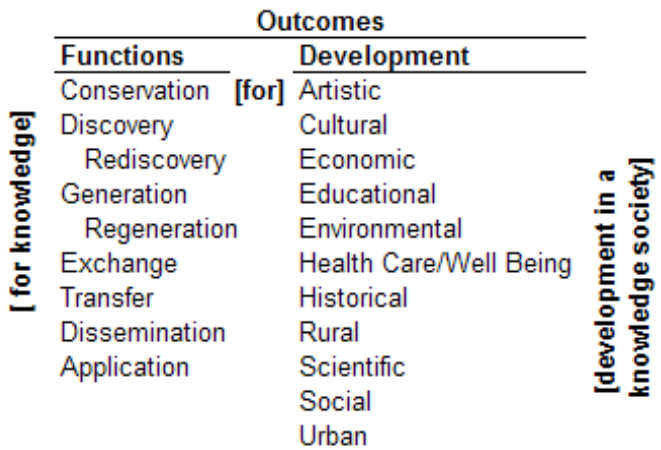

Figure 2: Ontology for Empowering a State for Development in a Knowledge Society focus areas of KKC constitution.

4. The sectors are described by two-level taxonomy. The University - a key anchor of the TH - has been broadened into the Education sector with University a component of that sector.

5. The Functions are expanded and relabeled to fit the context. Recognizing the importance of historical and traditional knowledge Conservation, Discovery, Rediscovery, and Regeneration have been added. Similarly, recognizing the importance of bridging the divide between different segments Dissemination has been added.

6. The Fields (of development) dimension has been renamed Development. The categories of Development have been refined and adapted to the vision and mission of KKC.

This ontology captures the core logic of empowering a state's development of a knowledge society. We discuss it in greater detail below.

\section{Functions of Knowledge Management for Development}

Knowledge in a society is voluminous, amorphous and multifaceted. Many types of knowledge are essential for the development of any society - especially a knowledge society; they are listed in the rightmost column of Figure 2 and will be discussed in the next section. In this section we describe the six functions which constitute the full cycle of knowledge management listed in the second column from the right in Figure 2, namely: (a) conservation, (b) discovery and rediscovery, (c) generation and regeneration, (d) exchange, (e) transfer, (f) dissemination, and (g) application of knowledge.

\section{Conservation of Knowledge}

All societies - developed, developing, and underdeveloped - encapsulate their vast amount of knowledge individually in their members' memories, and collectively in their groups, organizations and repositories. They propagate knowledge about norms, values, culture, traditions, history, resources, agriculture, production of goods and services, health, and every facet of the people's life - the society's historical, traditional knowledge. This 
knowledge may be explicit and tacit, formal and informal, oral and written, procedural and declarative, encoded and not encoded, and so on. The conservation of this collective knowledge is critical for the continuity of the society and central to its development for there is a mutual dependence between the society and its knowledge. The society sustains the knowledge and the knowledge sustains the society. When the mutuality is virtuous - positively reinforcing each other - the development will be positive; when it is vicious - negatively reinforcing each other the development will be negative. Systematic conservation of a society's traditional knowledge can make discovery and rediscovery easier; ad hoc conservation would make it difficult, if not impossible.

\section{Discovery and Rediscovery of Knowledge}

The vast amount of a society's knowledge is encapsulated in its collective unconscious is often unknown to most people and is not easily knowable. However, in this knowledge may be present the solution to many problems of development and the barriers to the implementation of some solutions. The hidden knowledge has to be discovered anew and rediscovered as and when needed. Systematically tapping the society's unconscious by facilitating the process of its discovery and rediscovery can limit the costs of trials and errors in development. In many areas of development, ground water management is one example, it has been found that the people knew the solution and practiced it in earlier times; that solution had to be discovered or discovered to solve the problem today.

\section{Generation and Regeneration of Knowledge}

Very often the solution to a problem requires new knowledge. New problems such as urban sprawl, new diseases such as HIV/AIDS, and new concerns such as childhood obesity have arisen due to the changes on society and its environment. At the same time, new solutions have become possible due to developments in science and technology. The new solutions have to be generated in the context of development; solutions successful elsewhere have to be regenerated in the local context.

\section{Exchange, Transfer, and Dissemination of Knowledge}

Free flow of knowledge is sine qua non for effective development. However, the flow has to be managed through exchange, transfer, and dissemination mechanisms. They make knowledge accessible by and available to everyone who needs it in a controlled and systematic manner. For example, a university faculty member may exchange papers with a faculty member in another university; a researcher may transfer a technology she has developed to a company for manufacturing; and a public health organization may disseminate information on vaccination against an impending epidemic. The 'Kanaja' portal of KKC is facilitating these functions of knowledge management.

\section{Application of Knowledge}

Knowledge has to be translated into action for a society's development; it has to be applied to solve the problems and corrected when it does not. Availability and accessibility of knowledge are necessary but not sufficient for application. The knowledge has to become embedded in the society's practices processes. For example, all the knowledge about water conservation would be of little value unless it is incorporated into the daily habits of the people in the society by changing how they cook, wash clothes, bathe. Application also provides feedback about the efficacy of the knowledge. A successful application reinforces its efficacy; an unsuccessful application signals the need for further research. Two projects of KKC relating to application of traditional health practices to public health management and development of regional pharmacopoeias have brought out the application of traditional knowledge existing for ages.

\section{Types of Development}

A sustainable knowledge society has to balance different types of development. KKC's focus is listed in the rightmost column of Figure 2. They are: artistic, cultural, economic, educational, environmental, health care/well being, historical, rural, scientific, social and urban development. The list can be expanded, shortened or refined in other contexts.

Each type of development draws upon its own base of knowledge with very different characteristics. Whereas knowledge for scientific development may be primarily in journals, knowledge for artistic development may be primarily in the minds of the artists. Consequently the functions for managing the knowledge for each may be very different. Continuing the example above, scientific knowledge can be disseminated by distributing the journals, whereas some artistic knowledge can be disseminated only through actual performance. The heterogeneity of knowledge for the different types of development requires a diverse management strategy. It is a major part of the challenge of organizations like KKC. 
The different types of development are dependent on each other. For example, educational development can foster economic development, and economic development can foster cultural development, which in turn can foster educational development. The complex network of relationships between the different types of development is being researched; some are well understood and some yet to be understood. For example, the impact of women's education (as opposed to men's) on family planning and consequently on family wellbeing was discovered only recently. Knowing about and managing each type of development and its interactions will be central to the success of KKC.

\section{Outcomes $=$ Functions of Knowledge Management $\mathbf{x}$ Types of Development}

The combination of 7 types of Functions and 11 types of Development comprehensively enumerate the 77 possible development Outcomes in a knowledge society. Some examples of these combinations are (a) knowledge conservation for artistic development, (b) knowledge exchange for rural development, and (c) knowledge dissemination for health care/well being development. While the complete list of 77 Outcomes may be desirable, it may not be feasible to devote adequate resources to all of them. The ontology gives a convenient way to map the current emphases as well as the desired ones. Thus, for example, knowledge generation for scientific development may be currently emphasized and desired. However, knowledge regeneration (of traditional knowledge) for environmental development may not be currently emphasized but desirable.

\section{Triple Helix Partnerships}

The TH Partnerships defined by the two Sectors and their Relationships are the mechanisms for obtaining the desired outcomes. These partnerships may be at the sector level, sub-sector level, or at the institutional level within each sub-sector. The institutions are not shown in the ontology. The relationships necessary for obtaining the desired Outcomes may range from complete independence (absence of a partnership) to symbiosis. Thus, the ontology provides a clear way to define the partners in the $\mathrm{TH}$ and the nature of the relationship between them required to obtain the desired Outcomes.

\section{Leadership}

After defining the Outcomes and the TH Partnerships necessary to obtain the Outcomes the task of leadership would be to construct those relationships. The construction may entail a combination of the six Leading categories. For example, the call for greater autonomy of universities can be articulated as 'Enhancing Government Sector x Higher Education Independence’. Similarly, the call for developing library consortia using ICT can be articulated as 'Enhancing Libraries x Libraries Collaboration'.

Thus, the ontology can be used to assess the combination of Leading roles, TH Partnerships, and Outcomes (a) currently in place, (b) desirable, and (c) potentially possible. These correspond to the states-of-the-practice, -need, and -art. Systematically mapping these three states and assessing the gaps between them will provide the basis for a systematic strategy to fulfill the development goals.

\section{Contributions and Implications}

Four KKC projects summarized below highlight the steps Karnataka is taking in the development of a knowledge society. They are early steps in the transformation focused primarily on the Government sector-University sector relationships. In these projects the Industry sector, the third leg of the TH partnership has had a limited role. However, its role is likely to expand in the future. The 'Ontology for Empowering a State for Development in a Knowledge Society' in Figure 2 provides a framework for mapping the KKC efforts and assessing the level of emphasis on the different components. Such an assessment in turn will help fill the gaps and modify the trajectory of the KKC.

\section{Innovative University - Towards Reforms in Higher Education}

There are 1200 colleges, 200 thousand students and nearly 10,000 teachers in the higher education sector in the state of Karnataka. There are twenty one universities which govern and guide higher education.

As a first step towards reform in higher education, Karnataka Knowledge Commission undertook the transformation of Mysore and Karnataka Universities as innovative universities. Fourteen months of efforts resulted in a draft 
legislation ready for approval by the Cabinet of Government of Karnataka. They include constitution of expert committee, wide ranging consultation, survey of primary and secondary data, constitution of a task force and preparation of draft legislation. The core logic of 'The Expert Committee on Reform and Rejuvenation of the Universities of Mysore and Karnataka' is summarized in the ontology in Figure 3. The focus of the committee has been ambitious and comprehensive. The proposed legislation, based on the report, involves overhaul of the existing structure, introduction of contemporary Governance mechanism, separate systems for unitary and affiliating functions of university, maximum autonomy from the Government and decentralization of authority and decision making. The walls of rigidity and isolation are broken in these universities. As a result, they set trend of innovation to other universities. In fact, they emerge as 'Mothers of Innovation'.

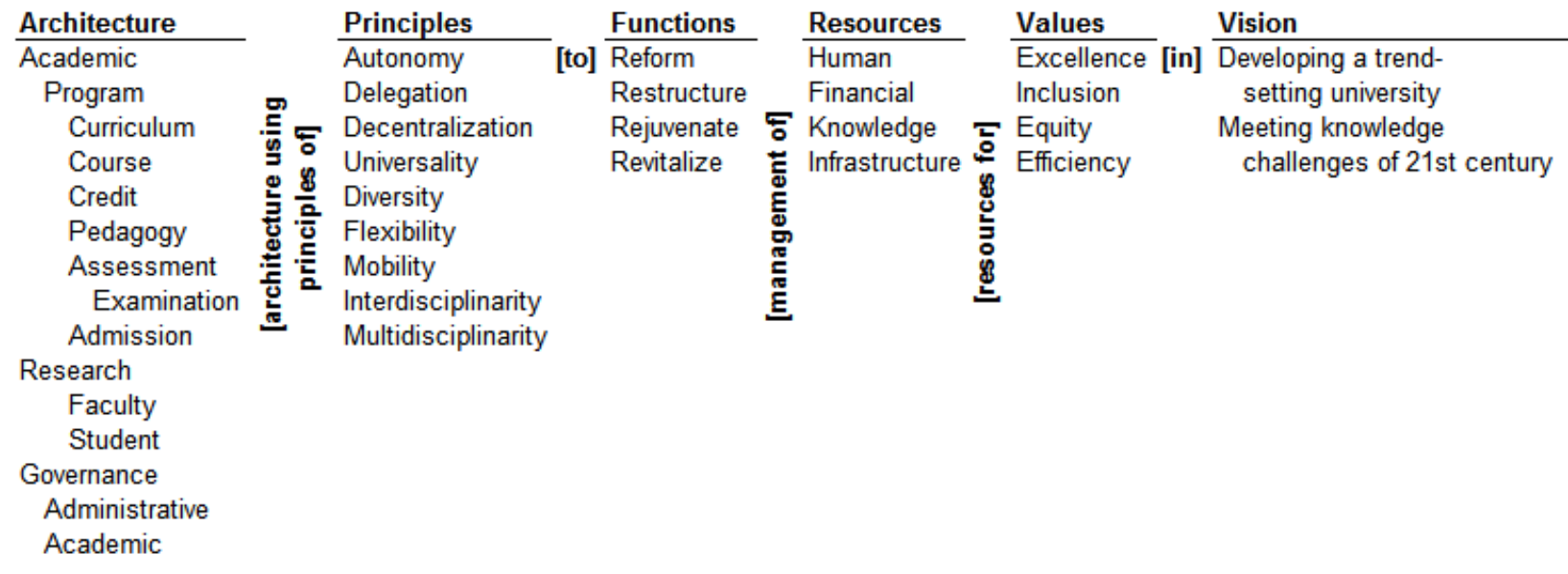

Figure 3: Core Logic of 'The Expert Committee on Reform and Rejuvenation of the Universities of Mysore and Karnataka'

\section{'Kanaja' - The World in Kannada}

Kannada is the native language of Karnataka. 'Kanaja' in Kannada means a storehouse, a granary. Building a knowledge society, in true sense of the term, requires capturing knowledge at the grass root levels and its dissemination. Then, the principle of 'knowledge exists in all and reaches all' becomes a reality. One appropriate strategy to realize this is the use of Internet and World Wide Web to create a knowledge 'Kanaja' (Kanaja).

Kanaja, an encyclopedic electronic portal in Kannada, is a pride project of Karnataka Knowledge Commission as a part of its vision 'transforming Karnataka into a vibrant knowledge society.' It is a portal in which anybody can participate, build and share any knowledge in Kannada. The needs of all sections, including farmers, housewives, children, disadvantaged sections who are all semi literate, have been taken into account while developing the concept as well as while designing content management system of the portal. It primarily caters to the needs of all those who read and write Kannada but not necessarily on Kannada.

\section{'Sahayog' - Towards Skill Development}

'Sahayog' (meaning mutual support in Kannada) is a project jointly launched by Department of Collegiate Education, Karnataka Vocational Training and Skill Development Corporation and Karnataka Knowledge Commission during 2010 (Karnataka Jnana Aayoga). This project involves Job and Life skill training of 120 hours (80+40 respectively) during 6th semester of BA, B.Sc, B.Com and BBM Courses in 111 Government degree colleges of 26 districts of Karnataka. 6250 students are benefited. The training was imparted during January and July, 2010. It encompasses appointment of nodal officers, training need assessment, delivery of training, provision of computers and broadband connectivity, supply of background material, assessment of candidates, organization of job fairs, feedback and impact study.

\section{'Arivu' - Building Effective and Functioning Libraries}

'Arivu' in Kannada is synonymous with the Sanskrit word for knowledge 'jnana'. It connotes learning, wisdom, awareness, consciousness. 'Arive guru' is a famous proverb in Kannada meaning 'knowledge is the master'. 
An effective and functioning library goes a long way in developing self-learning habits among children. The libraries can emerge as knowledge centers in Government High Schools of Karnataka. Adopting, building and mentoring these libraries over a period of time will contribute to improving the quality of learning in the schools. Open access and student friendly characteristics of these libraries make them 'Open Libraries'.

'Arivu' is a pilot project under which the Department of Primary and Secondary Education and KKC have adopted 225 Government High Schools for developing effective and functioning libraries (Karnataka Jnana Aayoga). An expert committee was constituted by KKC for guiding the entire gamut of activities for the project. Focus Group Discussion of high school teachers, one day workshop for teachers of 225 high schools, publication of manual on open library in Kannada, supply of books, AV materials and racks and appropriate mentoring of schools for developing effective and functioning school libraries and impact study after three months are some of the activities contemplated under 'ARIVU' project.

\section{Summary and Conclusion}

Symbiotic relationship between knowledge and society could be positively reinforced through empowering a state's development of a knowledge society. The big picture of strategy for development of such a society can be developed by strengthening the role of Triple Helix of Government, University and Industry through innovation, competition and sustainability. There is need for flexible, adaptable, coherent and complete framework for this purpose.

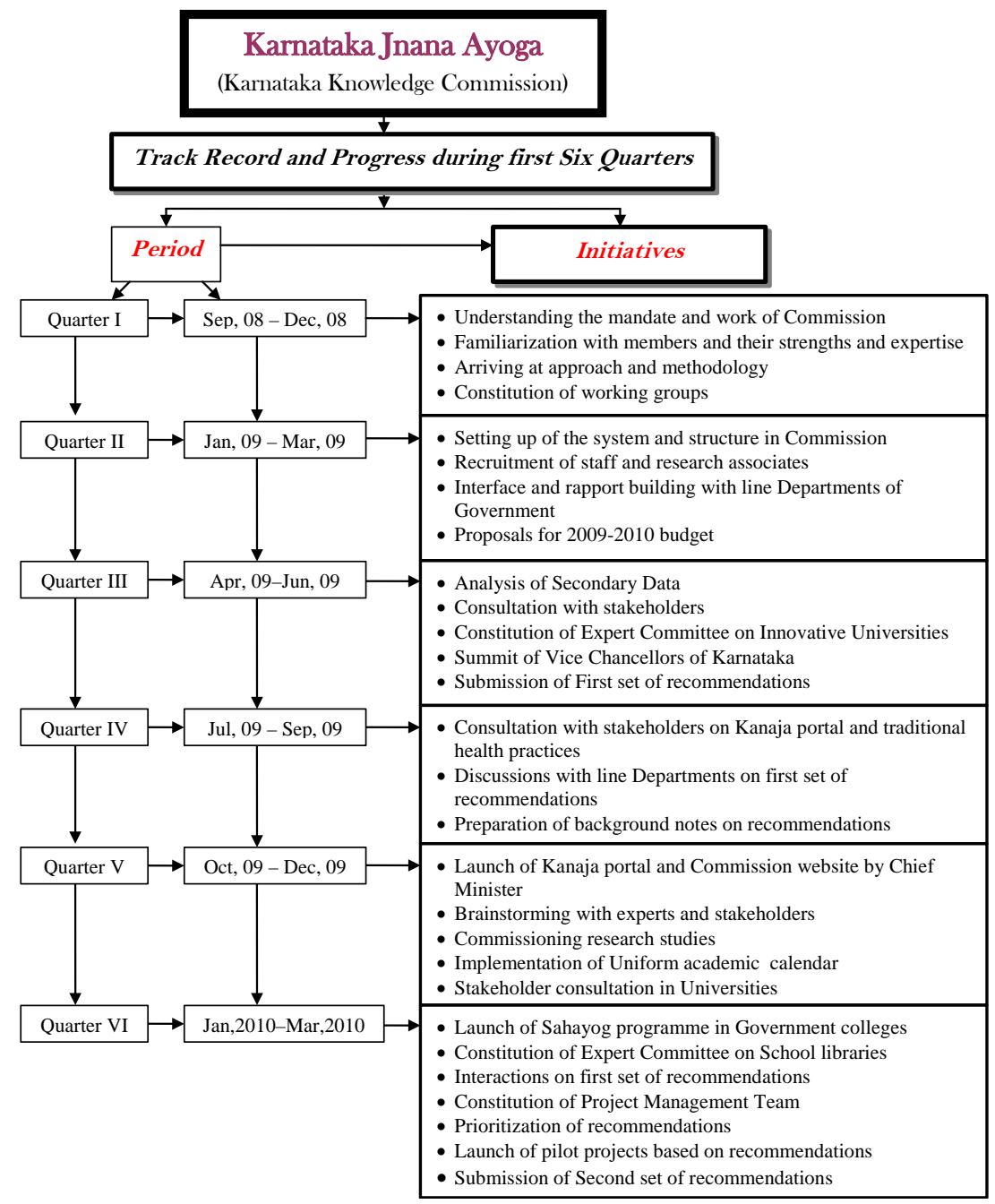

Figure 4: Karnataka Knowledge Commission Quarterly Progress 
Karnataka Knowledge Commission (KKC) provides a case study of such a framework. The adapted Triple Helix Ontology suggested by the authors in this paper gives a meaningful and constructive direction to all such efforts in other countries of the world and other states of India. The flowchart in Figure 4 below highlights KKC's systematic approach to realizing its vision.

\section{References}

Anandakrishnan, M. (2007). Critique of Knowledge Commission. Economic and Political Weekly: 557-560.

Anderson, W. T. (2007). "Knowledge in evolution." Futures 39(8): 915-919.

Bhargava, P. M. (2007). "How to make India a knowledge-based society." Futures 39(8): 997-1007.

Britz, J. J., P. J. Lor, et al. (2006). "Africa as a knowledge society: A reality check." The International Information \& Library Review 38(1): 25-40.

Casey, C. (2006). "A knowledge economy and a learning society: a comparative analysis of New Zealand and Australian experiences." Compare: A Journal of Comparative and International Education 36(3): 343-357.

Commission of the European Communities. (2006). "Delivering on the Modernisation Agenda for Universities: Education, Research and Innovation." Retrieved July 20, 2008, from http://ec.europa.eu/education/policies/2010/doc/comuniv2006_en.pdf.

Commission of the European Communities. (2006). "The European Institute of Technology: further steps towards its creation." Retrieved July 20, 2008, from http://ec.europa.eu/education/policies/educ/eit/comm_8_6_06_en.pdf.

Frank, D. and J. Meyer (2007). "University expansion and the knowledge society." Theory and Society 36(4): 287311.

Ghosh, M. (2009). "Digital infrastructure and attitudes towards access and sharing: A case study of selected engineering libraries in the Maharashtra state of India." The International Information \& Library Review 41(2): 89-120.

Jakobi, A. P. (2007). "The Knowledge Society and Global Dynamics in Education Politics." European Educational Research Journal 6(1): 39-51.

Kalfoglou, Y. (2007). "Knowledge society arguments revisited in the semantic technologies era." International Journal of Knowledge and Learning 3(2): 225-244.

Kanaja. Retrieved August 30, 2010, from www.kanaja.in.

Karnataka Jnana Aayoga. Retrieved August 30, 2010, from www.jnanaayoga.in.

Karnataka Knowledge Commission (2009). Sixth Quarterly Report (January 1 - March 31, 2009) available at http://www.jnanaayoga.in/document/quartely_reports/QR_6.pdf.

Karnataka State Gazette Notification (September 5, 2008).

Maria de Lourdes, M., F. Minoo, et al. (2004). "The Status of Strategic Planning in Portuguese Higher Education Institutions: Trappings or Substance?" Higher Education Policy 17: 383-404.

McElhinney, S. (2005). "Exposing the interests: decoding the promise of the global knowledge society." New Media \& Society 7(6): 748-769.

Mioduser, D., R. Nachmias, et al. (2008). New Literacies for the Knowledge Society. International Handbook of Information Technology in Primary and Secondary Education. J. Voogt and G. Knezek, Springer US. 20: $23-42$.

Mohrman, K. (2005). "World-Class Universities and Chinese Higher Education Reform." Retrieved July 20, 2008, from http://www.bc.edu/bc_org/avp/soe/cihe/newsletter/News39/text013.htm.

National Knowledge Commission. (2006). "NKC Note on Higher Education." Retrieved July 21, 2008, from http://knowledgecommission.gov.in/downloads/recommendations/HigherEducationNote.pdf.

National Knowledge Commission. (2006). "NKC Recommendations on Higher Education." Retrieved July 21, 2008, from http://knowledgecommission.gov.in/downloads/recommendations/HigherEducationLetterPM.pdf.

National Knowledge Commission (2009). Report to the Nation 2006-2009, available at http://www.knowledgecommission.gov.in/downloads/report2009/eng/report09.pdf.

Nokkala, T. (2005). "Knowledge society/knowledge economy discourse in internationalisation of higher education. A case study in governmentality." The Bologna Process and the Shaping of the Future of Knowledge Societies: 94-117.

O'Hara, M. (2007). "Strangers in a strange land: Knowing, learning and education for the global knowledge society." Futures 39(8): 930-941. 
Pillania, R. K. (2005). "Leveraging Knowledge: Indian Industry's Expectations and Shortcomings." Global Business Review 6(2): 231-249.

Pujar, S. M., R. K. Kamat, et al. (2008). "Identifying and exploiting human needs for a people centric evolving knowledge society: A case study of Indian ICT Emergence." The International Information \& Library Review 40(3): 165-170.

Radhakrishnan, S. (2007). "Rethinking knowledge for development: Transnational knowledge professionals and the "new" India." Theory and Society 36(2): 141-159.

Ramaprasad, A. and A. I. La Paz (2009). "The Role of Triple Helix in the Global Agenda for Innovation, Competitiveness and Sustainability: An Ontological Framework." Proceedings of Triple Helix, Vol. 7, June 2009. Available at http://ssrn.com/abstract $=1388724$.

Ramaprasad, A. and S. S. Papagari (2009). Ontological Design. Proceedings of DESRIST 2009. Malvern, PA, available at SSRN: http://ssrn.com/abstract $=1335984$

Rao, S. and I. V. Malhan (2008). "Transforming Indian farmers to reach the next level of the green revolution through communication of strategic knowledge and increased use of ICTs." The International Information \& Library Review 40(3): 171-178.

Rochdi, N. (2005). Confronting the Challenge of the Information and Knowledge Society in Developing Countries. Upon What Does the Turtle Stand? A. Aviram and J. Richardson, Springer Netherlands: 41-50.

Saloma-Akpedonu, C. (2008). "Malaysian Technological Elite: Specifics of a Knowledge Society in a Developing Country." Perspectives on Global Development \& Technology 7(1): 1-14.

Tilak, J. B. G. (2007). Knowledge Commission and Higher Education. Economic and Political Weekly: 630-633.

Tripathi, M. (2006). "Transforming India into a knowledge economy through information communication technologies--Current developments." The International Information \& Library Review 38(3): 139-146.

Tripathi, M. (2007). "Lokvani (voice of the masses): A case study of e-governance in rural India." The International Information \& Library Review 39(3-4): 194-202.

Weber, L. E. (2006). European Strategy to promote the Knowledge Society as a Source of renewed economic Dynamism and of social Cohesion. Universities and Business: Partnering for the Knowledge Society. L. E. Weber and J. J. Duderstadt. London, Economica: 3-18.

World Development Report (1998/1999). Knowledge for Development. New York, Oxford University Press. 